\title{
Hasta no verte Jesús mío: uma leitura descolonial de Josefina Bórquez
}

\author{
Maria Mirtis Caser* \\ Mariana Marise Fernandes Leite**
}

\begin{abstract}
Resumo
Este artigo analisa a obra Hasta no verte Jesús Mío, de Elena Poniatowska, propondo a possibilidade de a narração, baseada em uma série de entrevistas cedidas por uma mexicana real chamada Josefina Bórquez, ser uma releitura crítica da realidade histórica e social na qual Bórquez viveu e da qual surgiram suas memórias. Desse ponto de vista, defende que essa releitura está em diálogo com o feminismo e, mais especificamente, com o conjunto de propostas a que se vincula o feminismo descolonial. Para tal fim, a análise parte do princípio de que o texto, pela ausência que possuiria de limites tanto em sua relação com a realidade, quanto em relação à ficção, como bem comprova o trabalho de Cynthia Steele (2018), é pertencente à gama de textos da tendência que Josefina Ludmer (2013) denomina de pós-autonomia. Apoia-se ainda em Elaine Showalter, em "A crítica feminista no território selvagem" (1994), e María Lugones em "Colonialidad y Género" (2018), Rumo Ao Feminismo Descolonial (2018) e Multiculturalismo radical y feminismos de mujeres de color (2018), para apresentar as semelhanças entre a narração e as noções de crítica feminista e de feminismo descolonial, de forma a apontá-lo como uma possível releitura descolonial da experiência original da qual foi criado.
\end{abstract}

Palavras-chave: Poniatowska - Hasta no verte Jesús mío. Pós-autonomia. Reescrita crítica - Feminismo Descolonial.

\section{Hasta no verte Jesús mío: una lectura descolonial de Josefina Bórquez}

\section{Resumen}

Este articulo analiza la obra Hasta no verte Jesús Mío, de Elena Poniatowska, proponiendo la posibilidad de que la narración, basada en entrevistas concedidas por una mexicana real de nombre Josefina Bórquez, sea una relectura crítica de la realidad histórica y social en la que Bórquez vivió y desde la cual han resultado sus memorias. Desde ese punto de vista, propone que esta relectura esté en estrecho diálogo con el feminismo y, aún más, con el agrupamiento de proposiciones a las cuales se asocia el feminismo descolonial. Para realizar este análisis, parte de la noción de que el texto de Poniatowska, por la ausencia de limites tanto en su relación con la realidad, cuanto en su relación con lo ficcional, ya atestado en la investigación de Cynthia Steele (2018) sobre la obra, pertenezca a un agrupamiento de textos de una tendencia que Josefina Ludmer (2013) llama póstautonomia. Se basa aún en Elaine Showalter en "A crítica feminista no território selvagem" (1994), y María Lugones em "Colonialidad y genero" (2018), Rumo ao feminismo descolonial (2018) y Multiculturalismo radical y feminismos de mujeres de color (2018), presentando las similitudes entre la narración y las ideas de critica feminista y del feminismo descolonial, de manera a interpretar el texto como una posible relectura descolonial de la experiencia original desde la cual se originó.

Palabras-claves: Poniatowska- Hasta no verte Jesús mío. Póstautonomia, Reescrita crítica. Feminismo Descolonial.

\footnotetext{
* Professora do Programa de Pós-Graduação em Letras (PPGL) da Universidade Federal do Espírito Santo (Ufes)

** Doutoranda do Programa de Pós-Graduação em Letras (PPGL) da Universidade Federal do Espírito Santo (Ufes)
} 
Neste trabalho, estudamos a obra Hasta no Verte Jesús Mío, da escritora mexicana Elena Poniatowska, dissertando sobre como a personagem Jesusa Palancares, narradora e protagonista da história, é constituída em seu narrar por um olhar crítico influenciado não só pela questão de opressão de gênero exercida pela sociedade patriarcal em que está inserida, mas também por questões de raça e de classe impostas pela colonização europeia a suas novas terras, entre elas a que viria a ser o México (país de Jesusa).

Para tal fim, partimos da percepção do texto de Hasta no Verte Jesús Mío (1985), enquanto um texto ligado à noção de pós-autonomia proposta por Josefina Ludmer (2013), e analisamos a narração de Jesusa como um texto no qual se cruzam as questões que buscamos ressaltar e que foram impostas ao seu contexto de produção desde o processo de colonização, usando para essa análise Elaine Showalter, em "A Crítica feminista no território selvagem” (1994), e María Lugones, em “Colonialidad y género" (2018), Rumo ao Feminismo Descolonial (2018) e Multiculturalismo radical y feminismos de Mujeres de color (2018).

\section{Hasta no verte Jesus Mío, literatura e ficção}

Hasta no verte Jesús Mío é uma narração em primeira pessoa, em que Jesusa Palancares, uma oaxaquenha nascida nos primeiros anos do século XX, conta, já em meados do século, detalhes de suas experiências vividas até então. Partindo de experiências mais recentes na religião da qual é seguidora, a "Obra espiritual", Jesusa rememora sua vida desde os primeiros anos de infância com a família, passando por sua participação como soldadeira na revolução mexicana de 1910, por seu casamento, pela morte do marido e por sua vida após a revolução, quando passa, ainda muito jovem, a mudar constantemente de cidades, trabalhando em casas de família, bares e fábricas, estabelecendo diferentes níveis de relações com aqueles com quem se encontra, o que se dá até o presente da narrativa.

A obra é inspirada na vida de uma mulher real chamada Josefina Borquez. Elena Poniatowska a entrevistou semanalmente durante o percurso de um ano e foi dessas entrevistas que Hasta no Verte Jesús Mío foi produzido e, para construir seu texto, a autora afirma ter feito toda e qualquer intervenção que considerasse necessária:

[...] utilicé las anedoctas, las ideas y muchos de los modismos de Jesusa Palancares, pero no podría afirmar que el relato es una transcripción directa de su vida, porque ella misma lo rechazaría. Maté a los personajes que me sobraban, eliminé cuanta sección espiritualista pude, elaboré donde me pareció necesario, podé, cosí, remendé, inventé (PONIATOWSKA apud STEELE, 1992, p. 158).

A narração é um texto situado em tempo e espaço reais. A história de Jesusa Palancares tem ponto de partida às vésperas da revolução mexicana de 1910, e narra, em detalhes, a situação das soldadeiras que acompanhavam os revolucionários durante o conflito e também fatos da revolução e da história do México, bem como aponta aspectos sociais e culturais do país. Tudo isso está vinculado aos dados retirados por Elena Poniatowska das entrevistas que lhe foram concedidas por Josefina Bórquez. Ao mesmo tempo, não é possível verificar o quanto há no texto de história real e o quanto há de intervenções estéticas resultantes da criação literária em sua produção. Devemos lembrar, no entanto, que essa característica não é exclusiva da obra em análise.

De Acordo com Josefina Ludmer, em "A Cidade: na ilha urbana" e "Identidades territoriais e produção do presente", ambos capítulos de Aqui América Latina: uma especulação (2013), há uma tendência, ao final do século XX, de eliminar as bipolaridades não só sociais e políticas, devido ao encerramento do mundo bipolar, mas também na literatura: “[...] caem por terra as divisões 
tradicionais entre formas nacionais e cosmopolitas, formas de realismo e de vanguarda, da 'literatura pura', ou da literatura social', podendo acabar até mesmo a diferenciação entre realidade histórica e ficção" (LUDMER, 2013, p. 115).

Desenvolvem-se então textos para os quais já não interessaria, de acordo com a autora, ser ou não ser literatura (LUDMER, 2013, p. 127), ou questões afins. Textos que, presentes e evidentes nos anos 2000, mas já uma tendência muito clara ao fim da guerra fria, se colocariam dentro e fora da literatura ao mesmo tempo, já não podendo ser lidos como mero realismo, ou a partir de referências ou verossimilhança (LUDMER, 2013, p. 129). Em textos que usam entrevistas, notícias, TV ou mesmo a internet para reproduzir o presente e a realidade de forma já não fica claro como antes quais são os limites ou os polos (LUDMER, 2013, p. 130), fazendo com que noções como a de autor, de ficção, de realidade histórica ou de classificações literárias não sejam mais tão evidentes, já que os textos são as duas coisas ao mesmo tempo (LUDMER, 2013, p. 131). A esses vários textos latino-americanos Josefina Ludmer denomina literatura pós-autônoma.

Apesar de a autora deixar claro em seu texto que essa é uma tendência mais evidente a partir da década de 90 do século XX e dos anos 2000, optamos por considerar Hasta no Verte Jesús Mío como um exemplo de texto que se aproximaria da pós-autonomia, uma vez que, apesar de ter sido, desde sua produção, extensamente discutido quanto a sua relação com literatura e realidade, não se pode afirmar com segurança que o texto é um testemunho, ou um romance de formação, ou que estabeleça exata relação com qualquer classificação literária clássica. E isso viria a se reafirmar pelo fato de que, como afirma Beatriz Sarlo (2007, p. 22-23), em Tempo passado: cultura da memória e guinada subjetiva,

[...] a linguagem liberta o aspecto mudo da experiência, redime-a de seu imediatismo ou de seu esquecimento e a transforma no comunicável, isto e, no comum. A narração inscreve a experiência numa temporalidade que não é a de seu acontecer (ameaçado desde seu próprio começo pela passagem do tempo e pelo irrepetível), mas a de sua lembrança. A narração também funda uma temporalidade, que a cada repetição e a cada variante torna a se atualizar.

Dessa forma, ainda que exista a experiência primeira vivida pela pessoa de Josefina Bórquez, essa experiência, ao se tornar comunicável, já se altera primeiro ao ser narrada pela oaxaquenha Elena Poniatowska e, depois, ao ser narrada no texto. Não é possível então delimitar realidade ou ficção na obra. Ao falar sobre o processo de produção da obra e sobre como esse processo se deu durante as entrevistas ou transcrições, Cynthia Steele, em Testimonio y autor/idad en Hasta no verte Jesus mio, de Elena Poniatowska (2018), fala em questões inclusive de pontos de vista ideológicos, de diferentes visões de mundo de Bórquez e Poniatowska e mesmo da linguagem de Jesusa, criada do dialeto de um grupo de mulheres em condições sociais semelhantes à de sua entrevistada. $\mathrm{O}$ que é possível, e desta afirmação partimos para nossa análise, é considerar que o contexto de produção da obra, somado às intervenções pessoais feitas no ato da escrita, é que torna viável a existência de Jesusa Palancares, a personagem, enquanto uma possível leitura crítica, que considera a experiência de múltiplas opressões instauradas nas ex-colônias desde o processo de colonização, da mulher real na qual foi baseada a narração escrita.

Consideramos o texto como uma leitura crítica, embasando-nos também nos apontamentos de Florencia Garramuño em "La narración de la experiência”, capítulo de La experiencia Opaca (2009), já que nesse capítulo a autora ressalta a importância do retorno da subjetividade e da experiência à literatura não como uma forma de crença fiel naquilo que é dito pelo testemunho:

Pero el cierto es que la vuelta al sujeto y a la experiencia que estas novelas escenifican, lejos de mostrar una confianza plena en lo real y en la experiencia, hacen de la literatura y su acercamiento aquélla una manera de exponer lo real como problema, acercándose a él 
de manera insidiosa y desconfiada, elaborando, de esta forma, una poética del real que trata de dar cuenta de un real que es, en su pleno acaecer, de contornos poco nítidos y esquivos (GARRAMUÑO, 2009, p. 103-104).

E é exatamente isso que propomos que Hasta no verte Jesús Mío faz: retoma a experiência primeira e a problematiza em narração, fazendo isso em vários aspectos entre os quais estão o que agora expomos.

\section{Feminismo e descolonialidade}

Para bem visualizar como a questão de gênero e o olhar feminista se encaixam na narração de Jesusa Palancares, recorremos a Elaine Showalter. Em seu texto, "A crítica feminista no território selvagem" (1994), a autora problematiza papéis e desafios de uma crítica literária feminista de seu tempo histórico, partindo da junção de duas noções básicas: a primeira, de Carolyn Heilbrun e Catherine Stimpson, de que a crítica feminista apresenta dois caminhos: um voltado para erros do passado e outro para possíveis esboços do futuro; e a segunda, de Matthew Arnold, de que os críticos literários, de modo geral, se encerrariam em um território selvagem antes mesmo de encontrarem seu espaço e reconhecimento. Para a autora, independentemente dos erros do passado ou dos esboços do futuro, a crítica literária feminista estaria sempre em um território selvagem, já que seria pioneira nesse território de predominância masculino.

A partir daí, Showalter aponta duas formas que essa crítica feminista toma ao desbravar o território selvagem: uma revisionista e outra ideológica. É na forma ideológica da crítica que nos atemos para analisar nosso texto.

De acordo com Showalter, a crítica ideológica, ou leitura feminista/crítica feminista seria aquela crítica que "[...] diz respeito à feminista como leitora e oferece leituras feministas dos textos que levam em consideração as imagens e estereótipos das mulheres na literatura, as omissões e falsos juízos sobre mulheres na crítica, e a mulher-signo nos sistemas semióticos" (SHOWALTER, 1994, p. 26). Servindo como intelectual libertadora, e aqui a autora cita Anette Kolodny, a crítica literária feminista reivindica os direitos de selecionar novos recortes e de libertar novos sentidos, uma vez que a feminista não reivindicaria diferentes interpretações definitivas, mas sim que sejam novas interpretações que apresentam mulheres como autoras e que decodifiquem, de forma consciente, a mulher enquanto signo (SHOWALTER, 1994, p. 26-27).

Uma vez que Hasta no verte Jesús Mío e, consequentemente, Jesusa Palancares são a leitura de uma realidade primeira que passou pelo processo de transformação pela linguagem, não seria essa narração um processo semelhante a esse de que fala Showalter? Não seria ele uma diferente interpretação, uma decodificação da realidade de uma mulher enquanto signo? Acreditamos que sim.

A personagem de Jesusa Palancares, ao longo de sua narração, observa e descreve a sua própria condição e a condição de mulheres em seu entorno com um olhar crítico, permeado por noções socialmente construídas sobre mulheres e homens, tais como o que cada um(a) deveria ser e fazer e quais comportamentos e funções deveriam ser/eram exercidos por eles e elas na sociedade.

Ainda muito jovem, Jesusa perde sua mãe e passa a ser cuidada por madrastas, por cunhadas e pela irmã, Petra. A partir do que a personagem narra dos primeiros anos de sua vida e da relação que estabelecia com essas mulheres, vemos já um ponto de vista socialmente construído. Quando sua irmã volta a viver com a família, salva por um homem que viria a ser seu companheiro, depois de um tempo desaparecida por ter sido capturada, ela assume por um tempo o papel de quem cuidaria de Jesusa e assim a personagem conta: 
El caso es que ya vivieron junto con nosotros y como Petra llegó de mujer de la casa, mi papá descargó su obligación en ella.

-Te encargo a tu hermanita. Cuídala, péinala, lávala, haz con ella todo lo que hace una madre. Ándale, ahora a ti te toca atenderla.

Como yo no me crié con la hermana, no la quería, ni decía que era mi hermana. Yo ya estaba acostumbrada a mano de hombre, a la mano de mi padre. (PONIATOWSKA, 1985, p. 31).

A Petra o pai entrega Jesusa, como um cargo que a moça deveria exercer, uma vez que se havia tornado a mulher da casa. A moça, como acontecia com as madrastas de Jesusa, deveria exercer um papel materno, cuidando, penteando e fazendo tudo o que deve fazer uma mãe, de acordo com a expectativa masculina.

Essa mesma visão sobre papéis sociais se estende à protagonista mesma. O que podemos ver quando Jesusa narra o próprio comportamento na infância: "Yo era muy hombrada y siempre me gustó jugar a la guerra, a las pedradas, a la rayuela, al trompo, a las canicas, a la lucha, a las patadas, a puras cosas de hombre, puro matar lagartijas a piedrazos, puro reventar iguanas contra las rocas" (PONIATOWSKA, 1985, p. 19-20). No trecho, a personagem atribui a si mesma a característica de hombrada que, enquanto no dicionário da real academia espanhola ${ }^{1}$ significa uma ação esforçada digna de prêmios, não sendo especificado se uma ação de homens ou mulheres, de acordo com o verbete presente no dicionário $\mathrm{Oxford}^{2}$ é uma ação própria de um homem valente e generoso. A mesma característica é reforçada como própria de homens pela frase "puras cosas de hombre", apontando que para a personagem os comportamentos de que fala são atribuídos ao sexo masculino.

Vemos também esse olhar na vida adulta da personagem. Quando Jesusa descreve outras personagens que com ela se cruzam na história, isso às vezes fica muito claro. É o caso da filha de um general da revolução com quem esbarra como soldadeira, acompanhando seu pai e, mais tarde, seu marido, Pedro, na revolução. A essa moça Jesusa chama de "machorra", por seu comportamento que muito se assemelharia ao papel de um general homem no contexto do conflito. É o caso também de Don José de la Luz, um homem que alugava a Jesusa uma das várias casas em que a mulher morou na sua vida pós- revolução. Sobre ele, Jesusa afirma:

Don Lucho era muy buena gente, porque los afeminados son más buenos que los machos. Como que su desgracia de ser mitad hombre y mitad mujer los hace mejores. Tenía buen corazón y era muy decente. Aquí en la casa se vestía de mujer. Bailaba con muchos remilgos. En las tardes se arreglaba para recibir a sus amigos. Se ponía sus aretes, su collar, sus medias, y de mujer era muy guapo. No, no le importaba que lo viéramos nosotros, ¿por qué, por qué había de importar si él se sentía mujer? Se ponía de hombre para salir a la calle, pero al atardecer llegaban a verlo muchos amigos y entonces hablaba como si fuera mujer: -¡Ay, que me duele esto! ¡Ay, que por qué llegaste tarde! Era muy amante de los trapos como nosotras. Bordados de chaquira, lentejuela, organdi. (PONIATOWSKA, 1985, p.186).

Essa noção de papéis e posições sociais emaranhada às percepções da personagem ficam ainda mais evidentes quando Jesusa reflete sobre o fato de seu conhecido usar roupas de mulher:

Yo me visto a veces de hombre y me encanta. Nomás que yo no puedo traer pantalones; en primer lugar porque estoy vieja y en segundo lugar no tengo ya por qué andar haciendo visiones, pero de gustarme, me gusta más ser hombre que mujer. Para todas las mujeres sería mejor ser hombre, seguro, porque es más divertido, es uno más libre y nadie se burla de uno. En cambio de mujer, a ninguna edad la pueden respetar, porque si es muchacha se la vacilan y si es vieja la chotean, sirve de risión porque ya no sopla. En cambio, el hombre vestido de hombre va y viene: se va y no viene y como es hombre ni quien le pare el alto.

1 Hombrada: Acción muy meritoria y esforzada (REAL ACADEMIA ESPAÑOLA, 2018).

2 Hombrada: Acción que se considera propia de un hombre valiente o generoso (OXFORD UNIVERSITY PRESS, 2018). 
¡Mil veces mejor ser hombre que mujer! Aunque yo hice todo lo que quise de joven, sé que todo es mejor en el hombre que en la mujer. ¡Bendita la mujer que quiere ser hombre! (PONIATOWSKA, 1985, p. 186).

Jesusa, a personagem, demonstra, nesse e em outros vários trechos, noções bem claras sobre o "ser homem" ou o "ser mulher", que, como no exemplo, apontam como esses papéis são mais ou menos libertadores de seu ponto de vista. Por vezes, sua visão aparece implícita mesmo em histórias que viveu. É o caso do que conta sobre Irmã Sebastiana, já no primeiro capítulo da obra. A irmã, conhecida de Jesusa da Obra Espiritual, religião que as duas frequentavam, era perturbada e adoecida pelo que a narradora conta serem lembranças de uma vida passada, em que Sebastiana havia sido um homem que fez inúmeras mulheres infelizes, abandonando-as e a seus filhos. A mulher estaria então pagando por suas ações enquanto homem na vida passada. Vemos que Jesusa, ao mesmo tempo que reforça papéis sociais de homens e mulheres, apresenta deles uma leitura crítica. Homens e mulheres se comportariam ou deveriam comportar-se de determinada forma e, ao mesmo tempo em que os desvios não são bem vistos, neles estaria não só o erro, mas também qualquer resistência, já que, “(p) ara todas las mujeres sería mejor ser hombre, seguro, porque es más divertido, es uno más libre y nadie se burla de uno" (PONIATOWSKA, 1985, p. 186), ou porque determinados comportamentos, típica e socialmente apontados como masculinos, como no caso do homem que a irmã Sebastiana haveria sido na vida passada, valem sorte de reprimenda.

Apontamos, dessa forma, o texto como uma leitura de uma realidade pré-existente em estreito diálogo com noções de feminismo, já que nessa passagem para a linguagem escrita abre portas para novas visões a respeito daquelas experiências ali apresentadas.

Arriscamos com isso dizer que há uma crítica que não se limita apenas a questões de gênero, mas levanta também questões de igual importância que com a opressão de gênero se cruzam. Retornamos então a Elaine Showalter e ressaltamos outro de seus apontamentos em "A crítica feminista no território selvagem", que diz respeito à importância da análise da escrita da mulher relacionada à cultura da mulher. Para a autora, "uma teoria da cultura incorpora ideias a respeito do corpo, da linguagem e da psique da mulher, mas as interpreta em relação a contextos sociais nos quais elas ocorrem" (SHOWALTER, 1994, p. 94), e esse olhar relacionado à cultura consideraria diferenças entre as próprias mulheres como escritoras, considerando-se aí em análise classe, raça, nacionalidade e história, tão significativos quanto gênero.

Para tratar especificamente dessa questão da abordagem feminista que toca o contexto específico de produção da obra, fazemos uma ponte entre este último apontamento de Showalter e o feminismo descolonial, de que fala María Lugones em "Colonialidad y género" (2018), Rumo ao feminismo descolonial (2018) e Multiculturalismo radical y feminismos de mujeres de color (2018).

Segundo Lugones, em Rumo ao feminismo descolonial, a modernidade organizaria o mundo em dicotomias, oposições, a partir de uma dicotomia central, que é a do humano e não humano. Ao centro e ao topo dessa dicotomia estaria o homem europeu, burguês, colonial moderno, civilizado, cristão, heterossexual e racional (LUGONES, 2018, p. 936) e, em oposição a ele, estaria uma série de grupos homogêneos, que apresentariam a falta de alguma dessas características. Exemplos desses grupos seriam o homem negro e a mulher branca.

Ocorre que, ao pensar-se em dicotomias entre grupos homogêneos, há grupos inteiros que não se fazem representados, uma vez que possuem mais de uma das características em oposição ao modelo de ser humano representado no centro desse sistema. Um grupo que é exemplo disso, aponta a autora, é o das mulheres negras, já que, sendo o grupo de mulheres e o de negros dois grupos homogêneos que não se misturam, a categoria mulher negra seria uma categoria vazia.

Essa categorização em verdade seria, de acordo com Lugones, resultado do processo colonial desde a primeira modernidade, aquela modernidade do momento da conquista colonial, por conta da 
missão civilizatória que impôs no processo colonial o pensamento eurocêntrico aos colonizados e, com ele, todas as dicotomias geradas da dicotomia central do humano e não humano.

Do ponto de vista do feminismo descolonial, essa categorização afetou inclusive o pensamento feminista, uma vez que o feminismo clássico, aquele teorizado durante o século XX, era um feminismo voltado para reinvindicações predominantemente de mulheres brancas e burguesas, como se esse grupo fosse uma representação universal do que seria mulher, acabando por excluir todas as outras possibilidades de mulher, entre elas a mulher negra.

A proposta de Lugones, como reação a esse feminismo que não abarca em realidade todas as mulheres, é que se reconheça que, atreladas ao problema da opressão de gênero, existem outras opressões que se sobrepõem a ela, numa perspectiva de interseccionalidade. Uma vez que o feminismo descolonial está vinculado à noção de colonialidade do poder, de Aníbal Quijano tomamos o conceito defendido pelo teórico peruano:

"Colonialidade" refere-se: à classificação das populações do mundo em termos de raças - a racialização das relações entre colonizadores e colonizados/as; à configuração de um novo sistema de exploração que articula em uma estrutura todas as formas de controle do trabalho em torno da hegemonia do capital, onde o trabalho está racializado (tanto o trabalho assalariado como a escravidão, o sistema de servos, e a pequena produção de bens tornaram-se formas racializadas de produção; todas eram formas novas na medida em que se constituíram a serviço do capitalismo); ao eurocentrismo como o novo modo de produção e controle da subjetividade; a um novo sistema de controle da autoridade coletiva em torno da hegemonia do Estado-nação que exclui as populações racializadas como inferiores do controle da autoridade coletiva. (QUIJANO, 1991, 1995; QUIJANO; WALLERSTEIN, 1992, apud LUGONES, 2018, p. 939).

A proposta é que essa perspectiva feminista reconheça e considere essa interseccionalidade de opressões vinculadas à colonialidade, ou seja, que abarque todas as mulheres que são influenciadas pelo resultado da acumulação das opressões do processo colonial, por processos de classificação de gênero, mas também de classe e raça. A essas mulheres, María Lugones, em "Colonialidad y género" (2018, p. 75) chama mulheres de color:

No se trata simplemente de un marcador racial, o de una reacción a la dominación racial, sino de un movimiento solidario horizontal. Mujeres de color es una frase que fue adoptada por las mujeres subalternas, víctimas de dominaciones múltiples en los Estados Unidos. "Mujer de Color" no apunta a una identidad que separa, sino a una coalición orgánica entre mujeres indígenas, mestizas, mulatas, negras: cherokees, puertorriqueñas, sioux, chicanas, mexicanas, pueblo, en fin, toda la trama compleja de las víctimas de la colonialidad del género.

Tendo isso em vista, tornamos ao nosso texto em análise.

A personagem Jesusa Palancares, como já dissemos, é uma mulher nascida no México, no início do século XX, que vive por um tempo como soldadeira na revolução mexicana e que, depois disso, vive de cidade em cidade trabalhando em casas de família, em fábricas e em bares, vivendo apenas do básico para sua sobrevivência e, dessa forma, pensando com base nos critérios de classe, é uma personagem que, dentro do sistema capitalista imposto pelo processo colonial, é uma representante de uma camada mais pobre da sociedade.

Além disso, Palancares tem seu olhar sobre si mesma e sobre os outros afetado por noções de raça, vinculada a resquícios do cristianismo, duas noções fundamentais impostas pela missão civilizatória:

Como no tenía pensamientos jugaba con la tierra, me gustaba harto tentarla, porque a los cinco años todavía vemos la tierra blanca. Nuestro Señor hizo toda su creación blanca a su imagen y semejanza, y se ha ido ennegreciendo con los años por el uso y la maldad. Por eso 
los niños chiquitos juegan con la tierra, porque la ven muy bonita, blanca, y a medida que crecen el demonio se va apoderando de ellos, de sus pensamientos, y les van transformando las cosas, ensuciándolas, cambiándoles el color, encharcándoselas (PONIATOWSKA, 1985, p. 19).

Considerando essas noções, ela julga a si mesma e a outros personagens, como no seguinte trecho, em que fala de sua cor e da cor dos irmãos: "Petra era trigueña, más prieta que yo. Yo tengo la cara quemada del sol pero no soy prieta, pero ella sí era oscura de cuerpo y cara. Salió más indita que yo. Dos sacamos el color de mi papá y los otros dos fueron prietitos. Efrén y Petra; Emiliano y yo, mitad y mitad" (PONIATOWSKA, 1985, p. 31).

A essas noções soma-se também uma percepção de classe e de superioridade ligada à ideia do eurocentrismo. Esta última fica muito clara na consideração que a personagem esboça sobre as patroas para quem trabalhava em casas de família. Cito:

Por eso cuando iba a encargar trabajo, yo luego decía:

-Bueno, si son mexicanos, no me den la dirección porque no voy.

Serán mis paisanos pero francamente no me avengo. No es que los extranjeros no manden, pero lo hacen de otro modo; son menos déspotas y no se meten en la vida de uno: "¿Ya fuiste a misa? ¡Vete a los ejercicios! ¿A qué horas llegaste anoche? No vayas a platicar con ningún hombre, eh, tú, porque nosotros no respondemos, eh, tú”. En aquel tiempo no había agencias de colocación (PONIATOWSKA, 1985, p. 245).

Tal entendimento aparece também de forma aguda quando ligado a questões idiomáticas, como se vê na valorização positiva de uma falante do castelhano: "Mi madrastra era otra clase de persona. Tenía estudio. Su mamá, la señora Fortunata, era tan ignorante como mi papá, indita de idioma, indita de idioma zapoteca, pero mi madrastra sabía la idioma y el castilla porque con todo y todo la señora Fortunata la mandó a la escuela (PONIATOWSKA, 1985, p.54).

E na reação do pai, ao surprender Jesusa falando uma língua que não a materna:

Mi papá se enojó porque yo venía hablando la idioma zapoteca con los muchachos tehuanos de la corporación. Ellos me hablaban en la idioma y yo les contestaba porque me enseñé de chica en Tehuantepec con la mamá de mi madrastra. Y mi papá me alcanzó y me regañó." (PONIATOWSKA, 1985, p. 78-79).

A isso soma-se também a consciência de Jesusa sobre si mesma: "Yo era um animal muy bruto, uma yegua muy arisca" (PONIATOWSKA, 1985, p. 161). Essa comparação que Jesusa faz a um animal aparece ainda em outros momentos vinculada à questão de gênero:

Los hombres son siempre abusivos. Como si eso fuera ser hombre. Ésa es la enfermedad de los mexicanos: creer que son muy charros porque se nos montan encima. Y se equivocan porque no todas somos sus yeguas mansas. Claro, muchos están acostumbrados a que les dicen cualquier majadería a las mujeres y ellas se les ríen, les dan por su lado y se van con ellos (PONIATOWSKA, 1985, p. 178).

Ocorre que essa noção da mulher não passiva, que reage ao homem, ou que tem um comportamento diferente daquele que é esperado, é muito semelhante à visão sobre a mulher colonizada como vista pela visão da colonialidade, inculcada aos colonizados pela missão civilizatório. De acordo com Lugones (2018, p. 937), os homens e mulheres colonizados, a partir desse ponto de vista, não seriam homens e mulheres, mas sim: (os homens) não humanos em relação ao homem civilizado e (as mulheres) não humanas em relação às mulheres civilizadas. Dessa forma, homens e mulheres colonizados seriam, tão somente, machos e fêmeas.

Jesusa reproduziria e colocaria em questão uma série de elementos que permeiam sua narração e 
que iriam além da noção da opressão do patriarcado sobre um modelo de mulher universal, levantando, ao longo do texto, noções relacionadas ao seu próprio contexto social, a sua classe, a suas origens indígenas, a sua relação com o outro e à relação de outros com compreensões sobre raça transversais a seu contexto.

Essas anotações justificam, a nosso ver, a proposta da narração e a personagem Jesusa, sua protagonista e narradora, como uma releitura da realidade na qual foi inspirada, uma vez que essa experiência original tornada em linguagem toca questões de gênero atravessadas por outras opressões que, pelo contexto pós-colonização no qual se insere e do qual deriva, estão latentes.

\section{Conclusão}

Neste trabalho levantamos a possibilidade de a obra Hasta no Verte Jesús Mío, que aqui colocamos em análise, ser observada como uma leitura crítica de viés feminista da realidade na qual se produziram as experiências narradas por Josefina Bórquez a Elena Poniatowska durante as entrevistas concedidas por Bórquez à escritora e que deram origem à narrativa em primeira pessoa da personagem Jesusa Palancares.

Com tal finalidade, primeiro demonstramos como o texto em questão faz parte da gama de textos aos quais Josefina Ludmer (2013) chama de literatura pós-autônoma, o que se dá, apontamos, pela impossibilidade de demarcar o quanto há da realidade, no texto, a partir do qual ele foi criado ou de ficção e criação da autora.

De forma a reafirmar esse ponto de vista, ressaltamos que a narração é, em realidade, uma transformação em linguagem escrita de uma experiência já transformada em linguagem pela própria Josefina Bórquez ao narrar suas memórias a Elena Poniatowska pela primeira vez. Por esse motivo, com base no apontamento de Beatriz Sarlo (2007) de que, ao mesmo tempo que a experiência tornada linguagem passa a poder ser compartilhada, ela, a todo momento em que é verbalizada, insere-se em uma nova temporalidade, acabando, dessa forma, por alterar-se a cada vez que passa pela linguagem, ressaltamos a inserção da história de Bórquez em novas temporalidades até que se produzisse o texto, sendo esse um aspecto que deixaria clara a impossibilidade de delimitar o que há no texto de realidade ou ficção.

Assim, encaminhando-nos já à possibilidade de o texto ser um olhar de viés feminista sob a realidade na qual foi inspirado, ressaltamos a tendência de que fala Florencia Garramuño (2009), surgida ao fim do século XX, de retomar a importância da subjetividade e da experiência dentro do texto, mas não sem um pouco de desconfiança, de forma a lançar um olhar crítico sobre aquela realidade na qual o texto literário se produz. Afirmamos assim que, sendo essa a possibilidade que levantamos para a produção de Hasta no Verte Jesús Mío, iniciamos nossa exposição a respeito das aproximações do texto com o papel da crítica feminista e, em diálogo com esse papel, das aproximações com noções derivadas do feminismo descolonial.

Partimos então de Elaine Showalter (1994) em "A crítica feminista no território selvagem" e apontamos o texto de Hasta no Verte Jesús Mío como uma possibilidade de, fazendo uma interpretação feminista da realidade narrada nas experiências de Bórquez, serem liberados novos sentidos dessa realidade, os quais não negariam outros sentidos ali existentes, mas agregariam a eles novas percepções.

Dessa forma, e estabelecendo conexão com noções do feminismo colonial, nos utilizamos ainda da importância ressaltada por Showalter da crítica feminista que avaliasse a importância do contexto social em uma análise feminista, em uma crítica ligada à cultura, que considerasse fatores como raça e classe, por exemplo, essenciais para seu olhar. 
A partir daí, pudemos demonstrar, com base nos textos "Colonialidad y género" (2018), Rumo ao feminismo descolonial (2018) e Multiculturalismo radical y feminismos de mujeres de color (2018), de María Lugones, as aproximações da narração de Hasta no verte Jesús Mío com o feminismo descolonial pelo fato de nela estar presente, a todo momento, a sobreposição das opressões de raça, classe e gêneros, que se entrelaçam no contexto social e histórico de produção da obra, produzido desde o período colonial. 


\section{Referências}

GARRAMUÑO, Florencia. La narración de la experiencia. In : GARRAMUÑO, Florencia. La experiencia opaca: literatura y desencanto. Buenos Aires: Fondo de cultura económica, 2009. p. 91-150.

LUDMER, Josefina. A Cidade: Na ilha Urbana. In: LUDMER, Josefina. Aqui América Latina: Uma especulação. Tradução de Rômulo Monte Alto. Belo Horizonte: UFMG, 2013. p. 115-125.

LUDMER, Josefina. Identidades territoriais e produção de presente: Literaturas pós-autônomas. In: LUDMER, Josefina. Aqui América Latina: Uma especulação. Tradução de Rômulo Monte Alto. Belo Horizonte: UFMG, 2013. p. 127-133.

LUGONES, María. Colonialidad y género. Disponível em: <http://dev.revistatabularasa.org/ numero-9/05lugones.pdf>. Acesso em: 26 dez. 2018.

LUGONES, María. Multiculturalismo radical y feminismos de mujeres de color. Disponível em: $<$ https://www.redalyc.org/pdf/592/59202503.pdf $>$. Acesso em: 26 dez. 2018.

LUGONES, María. Rumo ao feminismo descolonial. Disponível em: < https://periodicos.ufsc.br/ index.php/ref/article/view/36755>. Acesso em: 26 dez. 2018.

OXFORD UNIVERSITY PRESS. Hombrada. Disponível em: <https://es.oxforddictionaries.com/ definicion/hombrada>. Acesso em: 12 dez. 2018.

PONIATOWSKA, Elena. Hasta no Verte Jesús Mío. Avena: Ediciones Era, 1985.

REALACADEMIA ESPAÑOLA. Hombrada. Disponível em: $<$ https://dle.rae.es/?id=KaR3MYj>. Acesso em: 12 dez. 2018.

SARLO, Beatriz. Tempo Passado: Cultura da memória e guinada subjetiva. Tradução de Rosa Freire D’Aguiar. Belo Horizonte; Companhia das Letras/ UFMG, 2007.

SHOWALTER, Elaine. A crítica feminista no território selvagem. In: BUARQUE DE HOLLANDA, Heloisa (Org.). Tendências e Impasses: o feminismo como crítica da cultura. Rio de Janeiro, 1994. p. 23-56.

STEELE, Cynthia. Testimonio y autor/idad en "Hasta no verte Jesus mio," de Elena Poniatowska. Disponível em: <http://www.jstor.org/stable/4530628>. Acesso em: 26 dez. 2018. 
